\title{
Assessment of Metabolic Syndrome and Its Risk Factors among Patients with Type 2 DM at Merjan Teaching Hospital, Al-Hilla City
}

\author{
Ali Hussein Alwan ${ }^{1}$; Ameer Alhusuny ${ }^{2}$ \\ ${ }^{1}$ Associate Professor Ali Hussein Alwan Internal Medicine, Diabetology and Endocrinology M.B.Ch.B, F.I.C.M \\ Department of Medicine College of Medicine/ University of Babylon \\ ${ }^{2}$ Lecturer AmeerAlhusuny Occupational Health and Epidemiology M.B.Ch.B, MSc Department of Community \\ Medicine College of Medicine/ University of Babylon
}

\begin{abstract}
:
Background: Metabolic Syndrome (MS) has become prevalent medical problem globally and the main consequence of Diabetes Mellitus (DM) and Coronary Heart Diseases (CHD). Aim of Study: To determine the proportion of MS among patients with type 2 DM and its association with MS risk factors at Merjan Teaching Hospital in Al-Hilla City. Materials and Methods: Ahospital-based cross sectional study design was carried out on (300) diabetic type 2 DM patients at diabetic outpatient clinic in Merjan Teaching Hospital. The study duration was from December 2011to December 2012. Categorical variables were presented as frequencies and percentages. Continuous variables were presented as means with their $95 \%$ confidence interval (CI) and standard deviation. The Pearson's chi-square test $\left(x^{2}\right)$ was used to determine the associations between categorical variables. Binary Logistic regression was done for multivariate analysis. A p-value of $<0.05$ was considered as statistically significant. Results: The results showedthat, out of 300 diabetic patients, the proportion of MS was $226(75.3 \%)$. The overall mean age of patients was $57.26 \pm 7.07$ years. (60.0\%) patients were male and (45.7\%) ofthe patients were from urban area. (60.0\%) of patients had abdominal obesity and (61.0\%) of patients adapt sedentary life style. (76.7\%) of patients had high triglyceride, meanwhile, only (39.7\%) had normal HDL. Hypertension was presented in (73.7\%) of patients. Metabolic syndrome was statistically significant with male, urban area, abdominal obesity, sedentary lifestyle, high triglyceride and hypertension.Patients with high triglyceride were 71 times more likely to develop MS than patients with normal triglyceride. Conclusion: High proportion of MS among diabetic type 2patients in this study. High triglyceride, urban area and sedentary lifestyle were the strongest predictors of $M S$.
\end{abstract}

Key words: Metabolic Syndrome (MS), Type 2 DM, High Triglyceride, Abdominal Obesity

\section{Introduction}

MS (syndrome X, insulin-resistant syndrome, dysmorphic metabolic syndrome and revean syndrome) is very common clinical condition and one of the major health public challenges due to its association with cardiovascular morbidity and mortality as well as complication of Diabetic Mellitus (DM) ${ }^{[1]}$. MS definition by the recent National Cholesterol Education Program (NCEP) and Adult Treatment Panel (ATP) III required three of the following abnormalities: waist circumference $>88 \mathrm{~cm}$ for women and $>102$ for men; fasting serum triglyceride $>1.7 \mathrm{mmol} / \mathrm{L}(150 \mathrm{mg} / \mathrm{dL})$ and $\mathrm{HDL}$ Cholesterol $<1 \mathrm{mmol} / \mathrm{L}(40 \mathrm{mg} / \mathrm{dL})$ for men and $<1.3$ $\mathrm{mmol} / \mathrm{L}(50 \mathrm{mg} / \mathrm{dL}$ ) for women; blood pressure $>130 / 85 \mathrm{mmHg}$ (or history of hypertension), or fasting blood sugar $(\mathrm{FBS})>5.7 \mathrm{mmol} / \mathrm{L}(100 \mathrm{mg} / \mathrm{dL}) \mathrm{b}^{[2]}$. There is another definition of MS according to the World Health Organization (WHO) includes either impaired FBS $>6.1 \mathrm{mmol} / \mathrm{L}(110 \mathrm{mg} / \mathrm{dL})$ or hyperinsulinemia plus two of the following: abdominal obesity (waist to hip ratio $>0.9$, Body Mass Index (BMI) $\geq 30 \mathrm{~kg} / \mathrm{m}^{2}$, waist girth $>94$ $\mathrm{cm}$ ); dyslipidemia (triglyceride $>150 \mathrm{mg} / \mathrm{dL}$ or $\mathrm{HDL}<40 \mathrm{mg} / \mathrm{dL}$ in men and $<50 \mathrm{mg} / \mathrm{dL}$ in women); hypertension (blood pressure 130/ $85 \mathrm{mmHg}$ ); microalbuminurea $\left(30-300 \mathrm{mg} / \mathrm{dL}\right.$ ) ${ }^{[3]}$. However, many authorities especially in last few years depend on NCEP- ATP III for definition of MS rather that of WHO criteria, because of accuracy, applicability and specificity of the former definition. The major determinant of MS is insulin resistance with resultant hyperinsulinemia which is the cause of type $2 \mathrm{DM}^{[4]}$. Greater researchesworldwide have been associated with increased rate of obesity, which is anticipated to dramatically increase prevalence of MS. The highest recorded prevalence was in Native America with nearly $(60 \%)$ for women aged 45-49 years and (45\%) for men aged 45-49 years according to NCEP and ATP III, meanwhile, it is (22\%) for women aged 45-49 years and (19.5\%) for men aged 45-49 years which is the lowest by the former record $^{[5]}$.

The pathogenesis of MS is still unclear despite of some risk factors which interact to cause this syndrome. Many components of MS have been associated with sedentary lifestyle including increase central 
adipose tissues, reduce HDL and a trend towards increase triglyceride, high blood pressure as well as glucose. So far, central obesity is one of the main causes of MS, which is responsible for insulin resistance at peripheral tissues $^{[6]}$. Grundy et al, 2005 reported in their study, MS is age dependent and associated with high prevalence worldwide ${ }^{[7]}$. In 2004, Popkin and Gordon- Larsen revealed increase prevalence of MS in type 2 diabetic patients or in those with impaired glucose tolerance (IGT).

Recently Fauci and his team attributed the pathogenesis of MS to Free Fatty Acids (FFAs) which is an expanded adipose tissue. FFAs results in an increase production of liver glucose, triglyceride as well as liver secretion of VLDL. Meanwhile, FFAs in periphery cause highLDL, low HDL as well as low peripheral insulin sensitivity ${ }^{[8]}$.

The term MS refersto the clustering of a number of cardiovascularrisk factors (obesity, hypertension,dyslipidemia, and hyperglycemia)believed to be related to insulin resistance.It is estimated that about $20-25 \%$ of theworld's adult population have MS, and they are twice as likely todie of and three times as likely to have aheart attack or stroke compared with peoplewithout MS. In addition,people with MS have afivefold greater risk of developing type $2 \mathrm{DM}^{[9]}$. Despite of highly prevalence for patients with type $2 \mathrm{DM}$, hypertension, dyslipedimia as well as sedentary lifestyle, the information about the prevalence of MS in Al-Hilla City is still lacked. This study has been carried out to determine the proportion of MS among patients with type $2 \mathrm{DM}$ and its association with MS risk factors at Merjan Teaching Hospital in Al-Hilla City.

\section{Study design/Study Location}

\section{Materials And Methods}

This hospital-based cross-sectional study was carried out in a tertiary centre (diabetic outpatient clinic in Merjan Teaching Hospital).

\section{Study population}

All patients with diagnosed type 2 DM seen at the diabetic outpatient clinic in Merjan Teaching Hospital between December 2011 and December 2012 were included in this study.

\section{Instruments and procedures}

The outcome variable was the Metabolic Syndrome (absence or presence), meanwhile, the independent variables wereage, sex, residence, waist circumference, Body Mass Index (BMI), triglyceride, HDL, sedentary life style and presence of hypertension.

\section{Blood Pressure Measurement}

Blood pressure has been measured using mercury sphygmomanometer (used for all patients who are not diagnosed previously), while the patients sitting for five minutes. The cut off was equal $\geq 130 / 85 \mathrm{mmHg}$ according to the NCEP or ATP III and did not depend on WHO criteria for diagnosis of hypertension.

\section{Abdominal Obesity}

NCEP or ATP III was the depending criteria to measure the waist circumference and determining abdominal obesity. A waist circumference of $>102 \mathrm{~cm}$ for male and $>88 \mathrm{~cm}$ for female have been obtained while the patient was standing up and the measurement at the level of umbilicus as the smallest girth between the costal margin and the iliac crests.

\section{Biochemical Estimation}

After a minimum of six fasting hours, five millilitres of venous blood was drawn from the antecubital vein of each participant. Separation was done using a centrifuge at $3000 \mathrm{round} /$ minute for about 15 minutes, the high density lipoprotein cholesterol (HDL-C) fraction was measured after precipitation of LDL-C and VLDL-C with dextran sulphate magnesium technique. Triglyceride estimation was measured by the enzymatic method. Accuracy was mentioned using commercial-quality control sera. The diagnosis of MS wasconfirmed by obtaining the measurements of FBS, waist circumference, triglyceride, HDL-C and blood pressure. According to ATP III criteria, patient who have three or more of the following criteria will defined as having MS: Abdominal obesity ( $>102$ and $>88 \mathrm{~cm}$ for men and women, respectively), hypertriglyceridemia $(>1.7 \mathrm{mmol} / \mathrm{L})$, low HDL-C $(<1$ and $<1.2 \mathrm{mmol} / \mathrm{L}$ for men and women, respectively) as well as blood pressure of $(>130 / 85$ $\mathrm{mmHg})$.

\section{Statistical Analysis}

Statistical analysis was carried out using SPSS version 18. Categorical variables were presented as frequencies and percentages. Continuous variables were presented as means with their $95 \%$ confidence interval (CI). The Pearson's chi-square test $\left(\mathrm{x}^{2}\right)$ test was used to determine the associations between categorical 
variables. Independent sample t-test was used to compare means between two groups.Binary Logistic regression was done for multivariate analysis. A $p$-value of $\leq 0.05$ was considered as statistically significant.

\section{Results}

Out of 300 patients with type $2 \mathrm{DM}, 226(75.3 \%)$ had with MS(Figure 1). The overall mean age of patients was $57.26 \pm 7.07$ years. Meanwhile, the mean age of diabetic patients with MS was $57.53 \pm 6.99$ years. There was significant differences of mean age for male $58.60 \pm 6.30$ years and female $55.70 \pm 7.01$ years $(\mathrm{t}=3.649$, $\mathrm{df}=298$ and $p<0.001)$, $(66.7 \%)$ of male patients were aged $\geq 60$ years (Figure 2$).(45.7 \%)$ ofpatients were from urban area (Figure 3). Figure 4 shows that, (73.3\%) of women were obese.

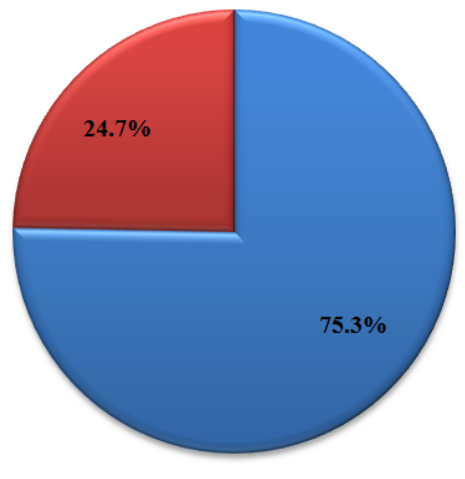

Metabolic Syndrome

- Non-Metabolic Syndrome

Figure 1: Distribution of patients by metabolic syndrome

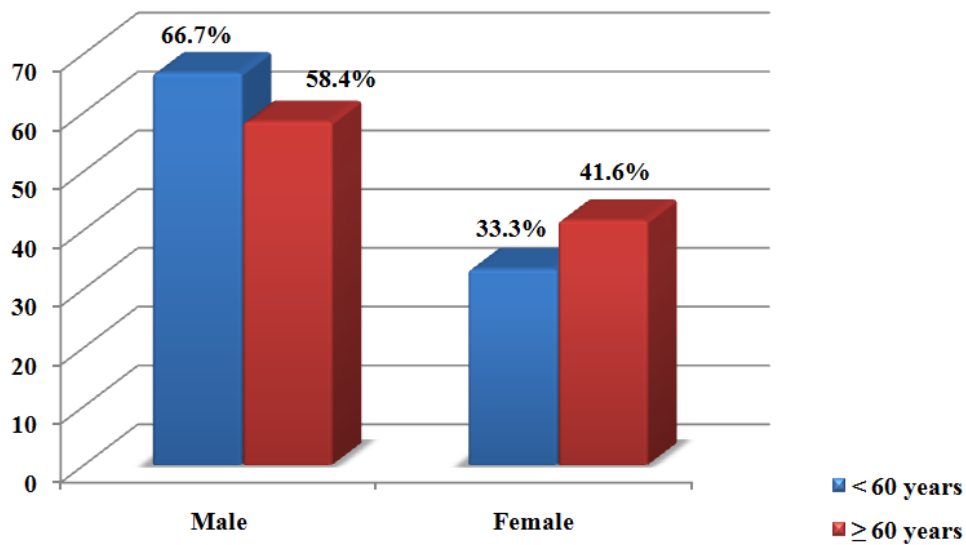

Figure 2: Mean differences of sex by age groups

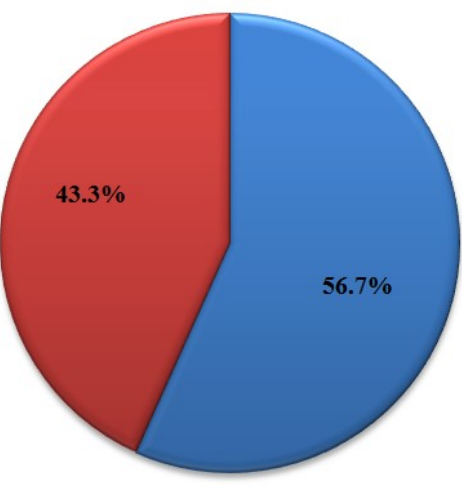

Figure 3: Distribution of patients by residence 


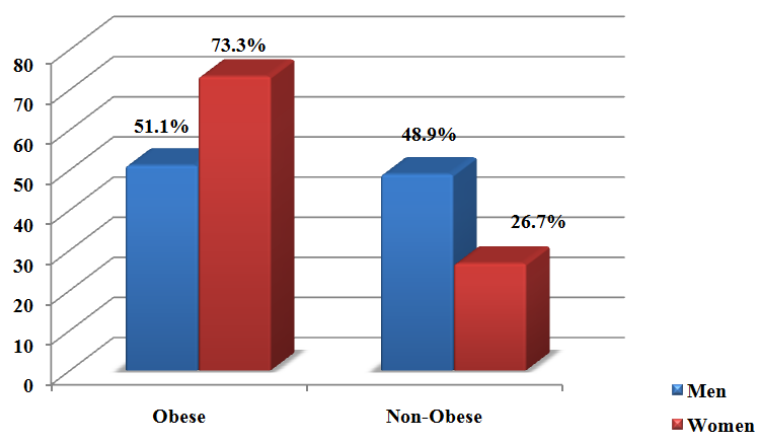

Figure 4: Distribution of sex by abdominal obesity

\section{Metabolic Syndrome and Its Associated Risk Factors}

Table 1 shows the distribution of metabolic syndrome by its risk factors waistcircumferences, BMI, abdominal obesity, life style, triglyceride, HDL and blood pressure. $(60.0 \%)$ of patients had abdominal obesity, meanwhile, $(61.0 \%)$ of the study patients adapted sedentary life style. $(76.7 \%)$ of patients had high triglyceride as well as, $(60.3 \%)$ of patients had low HDL. (73.7\%) of patients had hypertension.

Table 1: Distribution of metabolic syndrome by its associated risk factors

\begin{tabular}{lll}
\hline Variable & Mean \pm SD & Frequency (\%) \\
\hline Waist circumference & $114.60 \pm 3.91$ & \\
BMI & $31.78 \pm 2.05$ & \\
Abdominal obesity & & \\
$\quad$ Yes & & $180(60.0 \%)$ \\
No & & $120(40.0 \%)$ \\
Life style & & $183(61.0 \%)$ \\
$\quad$ Sedentary life style & & $117(39.0 \%)$ \\
$\quad$ Non-Sedentary life style & & \\
Triglyceride & $3.33 \pm 0.60$ & $230(76.7 \%)$ \\
$\quad$ High & & $70(23.3)$ \\
$\quad$ Normal & & \\
HDL & $0.75 \pm 0.06$ & $119(39.7 \%)$ \\
$\quad$ Normal & & $181(60.3 \%)$ \\
Low & & \\
Blood pressure & & $221(73.7 \%)$ \\
$\quad$ Hypertension & & $79(26.3 \%)$ \\
$\quad$ Non-Hypertension & & \\
\hline
\end{tabular}

\section{Association of Metabolic Syndrome and Patient's Socio-Demographic Characteristics}

Table 2 shows the association of metabolic syndrome and patient's socio-demographic characteristics. There were significant association between metabolic syndrome with sex and residence, meanwhile there was no significant association between metabolic syndrome and age.

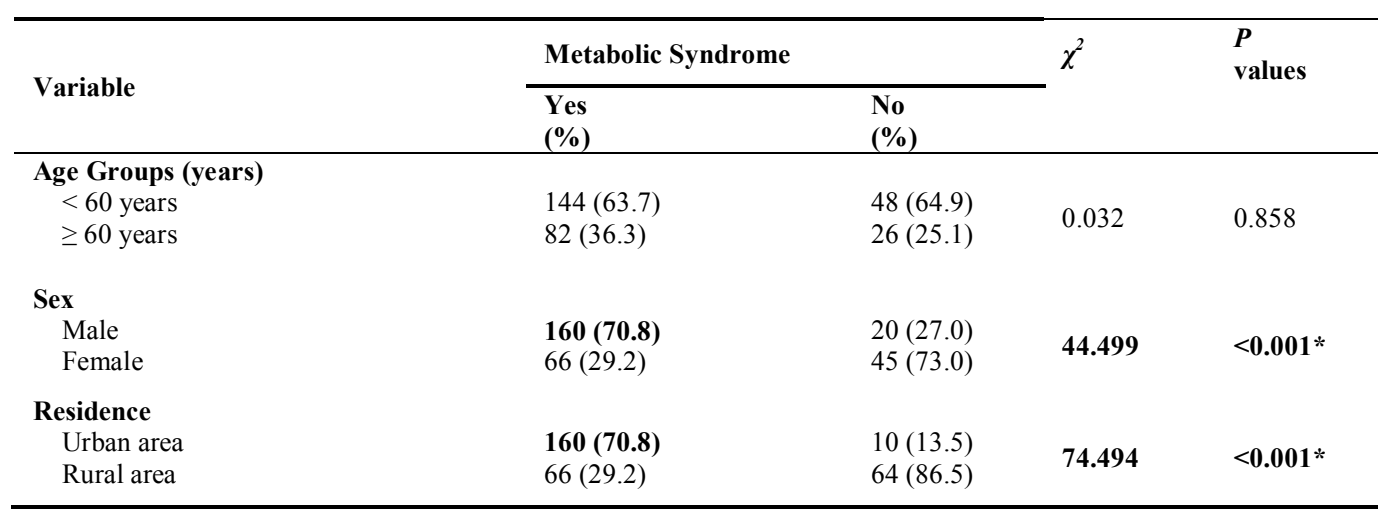

Table 2: Association of metabolic syndrome and patient's socio-demographic characteristics 
$* p$ value $\leq 0.05$ is significant

\section{Association of Metabolic Syndrome withIts Associated Risk Factors}

Table 3 shows the association of metabolic syndrome with its risk factors. There were significant association between metabolic syndrome with abdominal obesity, life style, triglyceride, HDL and blood pressure.

Table 3: Association of metabolic syndrome with Its Associated Risk Factors

\begin{tabular}{|c|c|c|c|c|}
\hline \multirow{2}{*}{ Variable } & \multicolumn{2}{|c|}{ Metabolic Syndrome } & \multirow[t]{2}{*}{$\chi^{2}$} & \multirow{2}{*}{$\begin{array}{l}P \\
\text { values }\end{array}$} \\
\hline & $\begin{array}{l}\text { Yes } \\
(\%)\end{array}$ & $\begin{array}{l}\text { No } \\
(\%)\end{array}$ & & \\
\hline \multicolumn{5}{|l|}{ Abdominal obesity } \\
\hline Obese & 158 (69.9) & $22(29.7)$ & \multirow{2}{*}{37.503} & \multirow{2}{*}{$<0.001 *$} \\
\hline Non-Obese & $68(30.1)$ & $52(70.3)$ & & \\
\hline \multicolumn{5}{|l|}{ Life style } \\
\hline Sedentary life style & $169(74.8)$ & $14(18.9)$ & \multirow{2}{*}{73.118} & \multirow{2}{*}{$<0.001 *$} \\
\hline No sedentary life style & $57(25.2)$ & $60(81.1)$ & & \\
\hline \multicolumn{5}{|l|}{ Triglyceride } \\
\hline High & $223(98.7)$ & $7(9.5)$ & \multirow{2}{*}{248.02} & \multirow{2}{*}{$<0.001 *$} \\
\hline Normal & $3(1.3)$ & $67(90.5)$ & & \\
\hline \multicolumn{5}{|l|}{ HDL } \\
\hline Low & $119(52.7)$ & $0(0.0)$ & \multirow{2}{*}{64.58} & \multirow{2}{*}{$<0.001$ * } \\
\hline Normal & $107(47.3)$ & $74(100.0)$ & & \\
\hline \multicolumn{5}{|l|}{ Blood pressure } \\
\hline Hypertension & $189(83.6)$ & $32(43.2)$ & \multirow{2}{*}{46.86} & \multirow{2}{*}{$<0.001 *$} \\
\hline Non-Hypertensive & $37(16.4)$ & $42(56.8)$ & & \\
\hline
\end{tabular}

*p value $\leq 0.05$ is significant

Logistic Regression Analysis ofMetabolic Syndrome as a Function of Associated Risk Factors

Table 5 shows the logistic regression. Only eight independent variables showed significant contribution to the model (sex, residence, abdominal obesity, lifestyle, triglyceride and hypertension). The strongest predictor of reporting MS was triglyceride. Diabetic patients with high triglyceride were71 times more likely to report MS than those with normal triglyceride. Patients from urban area, adapted sedentary life style female sex, hypertensive and obese patients were $15,12,6$ as well as 5 times more likely to report MS than other patients.

Table 5: Logistic Regression Analysis ofMetabolic Syndrome as a Function of Associated Risk Factors

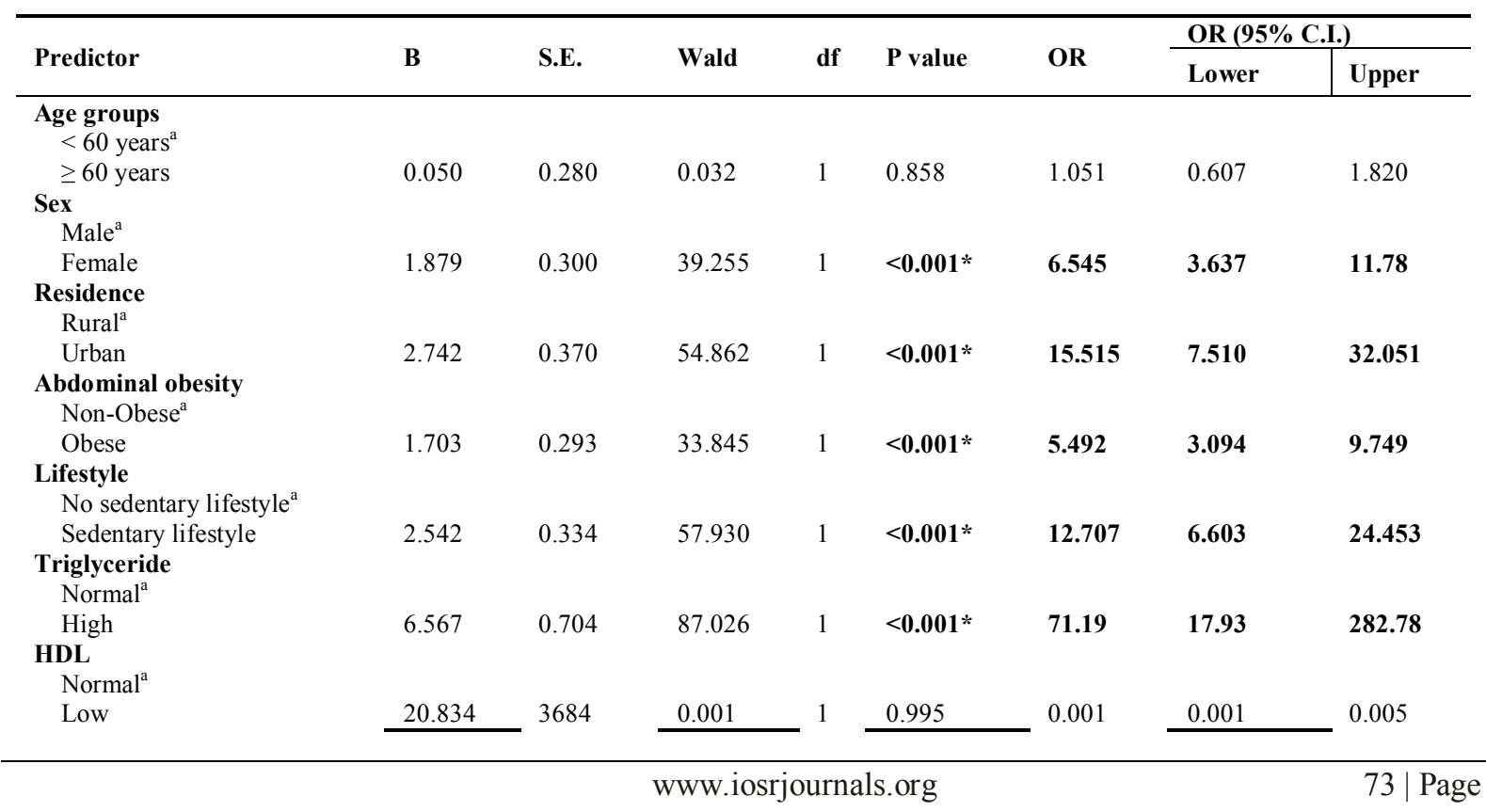




\begin{tabular}{|c|c|c|c|c|c|c|c|c|}
\hline \multicolumn{9}{|l|}{$\begin{array}{l}\text { Blood pressure } \\
\text { Non-Hypertension }^{\mathrm{a}}\end{array}$} \\
\hline Hypertension & 1.903 & 0.296 & 41.435 & 1 & $<0.001 *$ & 6.704 & 3.756 & 11.967 \\
\hline Constant & 0.712 & 1.944 & 0.134 & 1 & 0.714 & 2.038 & & \\
\hline
\end{tabular}

\section{${ }^{a}$ Reference category, " $p$ significant when $p \leq 0.05$ Nagelkerke $R^{2}=0.483$, Binary Logistic Regression: Enter}

\section{Discussion}

MS is increasing in prevalence, paralleling an increasing epidemic of obesity. In the United States, more than one fourth of the population meets diagnostic criteria for MS which is approximately the same prevalence forEuropean population and Latin America ${ }^{[10]}$. Meanwhile,the prevalence of MS in East Asia may range from $8-13 \%$ in men and from $2-18 \%$ in women, depending on the population and definitions used ${ }^{[11-}$ ${ }^{14]}$. Many reports have been published on the prevalence of the MS in the Middle East. A community-based, cross-sectional survey in Basrah (Iraq) reported the optimal cutoff point of waist circumference for the diagnosis of MS as $99 \mathrm{~cm}$ in women and $97 \mathrm{~cm}$ in $\operatorname{men}^{[15-17]}$. However, a larger study on the prevalence of MS in the Middle East have been conducted in Iran, the age-standardized prevalence of the MS was about $34.7 \%$ and $37.4 \%$ based on the ATP III and IDF definition, respectively ${ }^{[18]}$. Meanwhile, a multinational study from 65 centers in six Middle Eastern countries (Bahrain, Kuwait, Qatar, Oman, United Arab Emirates, and Yemen) evaluated the prevalence and effect of MS based on IDF diagnostic criteria. MS was highly prevalent among patients presenting with acute coronary syndrome ${ }^{[19]}$. Furthermore, in a nationwide study in Egypt,central obesity was estimated in the study to be $29 \%$ with a more prevalence in women ${ }^{[20]}$. In addition Turkey survey according to ATP III guideline reported a prevalence of $33.9 \%$ for MS, with a higher prevalence in women $(39.6 \%)$ than in men $(28 \%)^{[21]}$.

The present study had been carried out to determine the presence as well as the components of MS for patients with type $2 \mathrm{DM}$ at diabetic outpatient clinic inMerjan Teaching Hospital Al-Hilla City. According to NECP and ATP III criteria that had been depended in this study, the proportion of MS was $75.3 \%$ among type 2 DM patients,however, there are differences between this finding and other findings by western countries attributed to the societies, lifestyles and races differences. In this study, women were more than men to develop MS, however, majority of women in current study were obese (Figure 4) as well as adapted lower level of physical activities and higher calories food. Furthermore, these findings were in agreement with other local, regional as well as global studies ${ }^{[12-24]}$.Meanwhile, this study was not in agreement with Finish study which reported that the prevalence of MS was higher among men than women due to higher men waist to hip ratio than women ${ }^{[25]}$. Patients from urban area were 15 times more likely to develop MS, however, these finding have been attributed to adapt sedentary lifestyle, physical inactivity as well as unhealthy food habits of people from urban area as reported in regional studies of Turkey, Iran and other studies ${ }^{[24,26}$ and 27$]$.Majority $(69.9 \%)$ of diabetic patients with MS in current study were obese, on other hand, those obese diabetic patients were five times more likely to develop MS. These finding were in agreement with Singaporean cohort study on central obesity in 2007, who revealed that central obesity could be as optional component of MS according to International Diabetes Federation (IDF), but these patients with central obesity were at a higher risk to develop

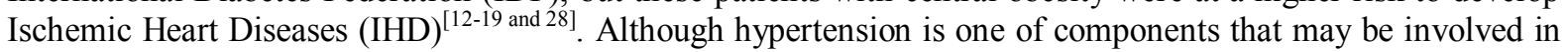
diagnosis of MS, diabetic patients with hypertension in this study were six times more likely to develop MS. However, adapting poor lifestyle and food habit as well as highly elevated fasting triglyceride by patients lead to poorly controlled blood pressure ${ }^{[28]}$.

Patients withhighly triglyceride level were the strongest predictor to develop MS in this study, patients with high triglyceride were 71 times more likely to develop MS than patients with normal triglyceride.Hypertriglyceridemia commonly occurs along withother components of the metabolic syndrome ${ }^{[29]}$. Anelevated triglyceride is the most availablelaboratory marker to uncover the coexistence of multiplerisk factors, including non-lipid risk factors, suchas hypertension ${ }^{[29}$ and 30$]$, elevated plasma glucose, and a prothromboticstate ${ }^{[29]}$. Hypertriglyceridemic patients thusmust be carefully evaluated for the other metabolicrisk factors that occur with the metabolic syndrome. Any patient whose triglyceride concentrations exceed $150 \mathrm{mg} / \mathrm{dL}$ is suspect for the metabolic syndrome ${ }^{[29-31]}$.Elevated serum triglycerides commonlyassociate with insulin resistance and represent avaluable clinical marker of the metabolic syndrome. The connections between insulin resistanceand atherogenicdyslipidemia, hypertension, a prothromboticstate, and glucose intolerance are complexand may be mediated through multiple metabolicpathways. 


\section{Conclusion}

Developing countries are undergoing an epidemiologic transition accompanied by increasing burden of CVD linked to urbanization and lifestyle modifications. MS is a cluster of CVD risk factors whose extent remains unknown. Among all the patients with type 2 DM have been received at outpatientsdiabetic clinic in Merjan Teaching Hospital from December 2011 to December 2012, the proportion of MS was (75.3\%). Diabetic patients with high triglyceride were71 more likely to developMS, followed by patients from urban area, sedentary lifestyle, female patients and patients with hypertension as well as abdominal obesity. However, there were no significant association between MS and age. This study has been provided appropriate data for MS in Al-Hilla City as well as a proper prediction of the main risk factors that highly associated with development of MS.

\section{References}

[1]. Felber JP, Golay A. Pathway from obesity to diabetes 2002.Int. J Obes, 2002; 26: S 39-45.

[2]. National Institutes of Health: Third Report of the National Cholesterol Education Program Export Panel on Detection, Evaluation and Treatment of High Blood Cholesterol in Adults (Adult Treatment Panel III), NIH Publication 01-3670, 2001.

[3]. Najarian RM, Sullivan LM. Metabolic syndrome compared with type 2 of DM as risk factors for stroke. Arch Intern Med J. 2006; 166 (13): 1418-19.

[4]. Liese AD, Mayer- Davis EJ, Haffner SM et al. Development of the multiple metabolic syndromes: an epidemiologic perspective. Epidemiol Rev, 1998; 20: 157- 172

[5]. Lakka HM, Laaksonen DE, Laka TA et al. The metabolic syndrome and total cardiovascular disease mortality in middle-aged men. JAMA, 2002; 288: 2709-2716

[6]. Garg A. Acquired and inherited lipodystrophies. N Engl J Med, 2004; 350: 1220-1234.

[7]. Grundy SM, Cleeman JI, Daniels SR et al. Diagnosis and management of the metabolic syndrome. An American Heart Association/ National Heart, Lung and Blood Institute Scientific Statement. Executive Summary. Cardiol Rev, 2005; 13: $322-327$.

[8]. Popkin B and Gordon- Larsen P. The nutrition transition: worldwide obesity dynamics and their determinants. Intl J Obesity, 2004; 28: S2- S9.

[9]. Fauci AS, Kasper DL, Braunwald E et al. Diagnostic metabolic syndrome. Harrison's principles of internal medicine. $17^{\text {th }}$ edition, 2008; 2: 1509-1513.

[10]. Sharma P and Mishra S. Metabolic syndrome: early identification prevents type 2 diabetes and cardiovascular disease. Indian $\mathbf{J}$ ClinBiochem, 2007; 22:1-3.

[11]. Grundy SM. Metabolic syndrome pandemic. ArteriosclerThrombVascBiol, 2008;28(4):629-36.

[12]. Ford ES, Giles WH, Mokdad AH. Increasing prevalence of the metabolic syndrome among U.S adults.Diabetes Care, 2004;27(10):2444-9.

[13]. Hoang KC, Le TV, Wong ND. The metabolic syndrome in East Asians. J CardiometabSyndr, 2007;2(4):276-82.

[14]. Hwang LC, Bai CH, Chen CJ. Prevalence of obesity and metabolic syndrome in Taiwan. J Formos Med Assoc, 2006;105(8):62635 .

[15]. Nestel P, Lyu R, Low LP, et al. Metabolic syndrome: recent prevalence in East and Southeast Asian populations. Asia Pac J ClinNutr, 2007;16(2):362-7.

[16]. Motlagh B, O’Donnell M, Yusuf S. Prevalence of cardiovascular risk factors in the Middle East: A systematic review. Eur J CardiovascPrevRehabil, 2009; 16:268-80.

[17]. Mansour AA, Al-Hassan AA, Al-Jazairi MI. Cut-off values for waist circumference in rural Iraqi adults for the diagnosis of metabolic syndrome. Rural Remote Health, 2007; 7:765.

[18]. Abu Sham'a RA, Darwazah AK, Kufri FH, Yassin IH, Torok NI. MetS and cardiovascular risk factors among Palestinians of East Jerusalem. East Mediterr Health J, 2009; 15:1464-73.

[19]. Delavari A, Hossein M, Alikhani S, Sharifian A. The First Nationwide study of the prevalence of the metabolic syndrome and optimal cut-off points of waist circumference in the Middle East: The national survey of risk factors for non-communicable diseases of Iran. Diabetes Care, 2009; 32: 1092-7.

[20]. Al Suwaidi J, Zubaid M, El-Menyar AA et al. Prevalence of the metabolic syndrome in patients with acute coronary syndrome in six middle eastern countries. J ClinHypertens, 2010; 12: 890-9.

[21]. Nasr GM, Sliem H, Gamal A et al. Screening for Diabetes and Cardiovascular Risk Factors among Egyptian population. Clinical Diabetes (Middle East edition), 2010; 9: 127-35.

[22]. Rennie KL andJebb SA. Prevalence of obesity in Great Britain. Obes Rev, 2005; 6: 11-2.

[23]. Abegunde DO, Mathers CD, Adam T et al. The burden and costs of chronic diseases in low-income and middle-income countries. Lancet, 2007; 370:1929-1938.

[24]. Huda Al-Ghareeb. Prevalence of metabolic syndrome. Journal of Family Medicine, 2007; vol. 5: issue 6.

[25]. Kaduka LU, Kombe Y, Kenya E et al. Prevalence of metabolic syndrome among an urban population in Kenya. Diabetic Care Journal, 2012; 35:887-893

[26]. Parikka-Ilanne P, Eriksson JG, Lindstrom J et al. Prevalence of the metabolic syndrome and its components. Finding from a Finnish general population sample and the diabetes prevention study cohort. Diabetic Care Journal, 2012; 27:2135-40.

[27]. Iham M, Aliakbar T, Gholam H. Multiparity and risk of MS, Isfahan Healthy Heart Program. MS and related Disorders J, 2009; 7 (6): 519-529.

[28]. Kalish GM, Barrett- Connor E, Laughlin GA et al. Association of endogenous sex hormones and insulin resistance among postmenopausal women: Results from the postmenopausal Estrogen/ Intervention Trail. J Clan Endocrinal Metab, 2003; 88: 164652 .

[29]. Lee J, Ma S, Tan CE et al. Should central obesity be an optional or essential component of metabolic syndrome? Ischemic heart disease risk in the Singapore cardiovascular cohort study. Diabetic Care Journal, 2007; 30:343-347.

[30]. Grundy SM. Hypertriglyceridemia, insulin resistance, and the metabolic syndrome. Am J Cardiol,1999;83:25-29.

[31]. Talayero BG and Sacks FM. The role of triglyceride in atherosclerosis. CurrCardiol Rep, 2011; 13: 6, 544-552.

[32]. JialalI,AmessW,Kaur M. Management of hypertriglyceridemia in the diabetic patient.CurrDiab Rep, 2010; 10:316-320. 